\title{
Knowledge, Attitude and Practice Study About Use of ORS in Diarrhea in Mothers with Children 02-05 Year Age Group Residing in Various Urban Slums of Bhopal City
}

\author{
Deepti Singh ${ }^{1}$, Sunita Lakhwani², D.P.S. Gaharwar ${ }^{3}$ \\ ${ }^{1,2}$ Associate Professor, Department of Paediatrics, R.K.D.F. Medical College Hospital \& Research Centre, Bhopal, ${ }^{3}$ Assistant Professor, Department of Paediatrics, R.K.D.F. \\ Medical College Hospital \& Research Centre, Bhopal.
}

\section{Abstract}

Background: KAP study for use of ORS in Diarrhea in mothers with children 02-05 year age group. The objective of the study was to assess the Knowledge, Attitude and Practice use of ORS in Diarrhea among mothers at various Urban Slums of Bhopal City. Subjects and Methods: A cross sectional descriptive study was conducted among mothers having children 02-05 year age group. All mothers were interviewed through a self designed pretested structured questionnaire regarding use of ORS in Diarrhea of their infants and socio demographic profile. Results: Majority of the mothers were illiterate, and not aware about benefits of use of ORS. Although mother's knowledge was lacking but most of mother use of ORS in Diarrhea in their children. Conclusion: Most of mothers do not follow practice of use of ORS in Diarrhea and had lack of knowledge. The knowledge regarding method of use of ORS for management of diarrhoea was found to be inadequate in this study. Though many mothers are aware that it is useful most are not aware of its method of use. More measures need to be adopted to improve this knowledge and make mothers aware about the method of use and availability of ORS.

Keywords: ORS, Diarrhea, Knowledge, Attitude, Practice, Urban Slums.

Corresponding Author: Dr. Sunita Lakhwani, Associate Professor, Department of Paediatrics, R.K.D.F. Medical College Hospital \& Research Centre, Bhopal.

Received: September 2019

Accepted: October 2019

\section{Introduction}

Diarrhoea is defined as the passage of three or more loose or liquid stools per day (or more frequent passage than is normal for the individual). Frequent passing of formed stools is not diarrhoea, nor is the passing of loose, "pasty" stools by breastfed babies. Diarrhoeal disorders in childhood reported in large proportion (18\%) of childhood deaths, with an estimated 1.8 million deaths per year globally. The World Health Organization (WHO) suspects that there are $>700$ million episodes of diarrhea annually in children $<5$ years of age in developing countries. ${ }^{[1]}$

The objective of this study was to see the change in knowledge and behavior of the mother acute diarrhea in children 02-05 years of age group. Because almost three decades have passed since commercially available ORS was launched and continued feeding during diarrhea is being stressed. ${ }^{[2,3]}$

Diarrhoeal disease is the 2nd principal cause of death in children under 05 years old, \& is responsible for killing around 760000 children every year. Diarrhoea can last several days, \& can leave the body without the water $\&$ salts that are necessary for survival. ${ }^{[4]}$ Most people who die from diarrhoea die from severe dehydration \& fluid loss. Children who are malnourished or have impaired immunity as well as people living with HIV are most at risk of life-threatening diarrhoea. It is usually a symptom of an infection in the intestinal tract, which can be caused by a variety of bacterial, viral and parasitic organisms. Infection is spread through contaminated food or drinking-water, or from person-to-person as a result of poor hygiene. ${ }^{[5]}$

\section{Subjects and Methods}

This study was conducted at various Urban Slums of Bhopal City. This cross sectional study was carried out from September 2018 to August 2019. All mothers who have 0205 years of age group child with diarrhea were enrolled. Total 300 consecutive mothers with written informed consent were taken.

A predesigned \& pretested questionnaire was prepared comprising of nearly 20 questions, most of the questions were close ended. Besides literacy, socioeconomic status was also noted. Questions pertained to practices towards diarrhea, nutrition during diarrhea and awareness of ORS. A single interviewer interviewed all 300 mothers who have 02 05 years of age group child for diarrhea and related diseases. 
It took nearly $15-20$ minutes to finish one interview \& on a single day, not more than 5 interviews were carried out. At the end of each interview, the mothers were provided with health education to improve their knowledge of diarrhea, nutrition during diarrhea and oral rehydration therapy, with practical demonstration of correct ORS preparation. Also, the mothers were handed over a health education pamphlet in Hindi pertaining to diarrhea and ORS at various Urban Slums of Bhopal City, to improve their knowledge and management skills in the future. The data was calculated in Microsoft Excel and interpreted as mean and percentages.

\section{Inclusion Criteria:}

Mothers with children of 02 to 05 yrs age group, who are permanent residents of urban slums.

\section{Exclusion Criteria:}

1. Mothers with either less than 02 years or more than 05 yrs age group children.

2. Mothers with children who are critically ill, hospitalized or on medication.

3. Mothers who are guests or temporary residents of urban slums.
Results

Table 1: Age of Mothers

\begin{tabular}{|l|l|l|}
\hline Age of mother & $\begin{array}{l}\text { No. of mother } \\
(\mathbf{n = 3 0 0})\end{array}$ & Percentage of mother \\
\hline Below 25 years & 53 & 17.66 \\
\hline 25-35 years & 179 & 59.66 \\
\hline 35 years and above & 68 & 22.68 \\
\hline
\end{tabular}

In our study, $59.66 \%$ were in age group of 25-35 years, followed by 22.68 were 35 years \& above \& $17.66 \%$ were below 25 years.

Table 2: Education of Mothers

\begin{tabular}{|l|l|l|}
\hline $\begin{array}{l}\text { Education of } \\
\text { mothers }\end{array}$ & $\begin{array}{l}\text { Number of mothers }(\mathbf{n}= \\
\mathbf{3 0 0})\end{array}$ & $\begin{array}{l}\text { Percentage of } \\
\text { mother }\end{array}$ \\
\hline Intermediate & 21 & 7.00 \\
\hline Primary & 97 & 32.34 \\
\hline Illiterate & 182 & 60.66 \\
\hline
\end{tabular}

In our study, $60 \%$ were Illiterate mothers, followed by 32.34

Primary \& $7 \%$ were Intermediate.

Table 3: Knowledge, Attitude and Practice study about use of ORS in Diarrhea in mothers

\begin{tabular}{|l|l|l|l|}
\hline S. No. & Parameter & Number of mothers $(\mathbf{n}=\mathbf{3 0 0})$ & Percentage of mothers \\
\hline 1 & Did not know the exact definition of diarrhoea & 267 & $91 \%$ \\
\hline 2 & Aware that diarrhoea leads to dehydration & 79 & $26.33 \%$ \\
\hline 3 & Food contamination causes diarrhea & 98 & $32.66 \%$ \\
\hline 4 & Rice based feeds are best in diarrhea & 112 & $37.34 \%$ \\
\hline 5 & Oral fluids should be increased in diarrhea & 96 & $31.88 \%$ \\
\hline 6 & Aware of ORS but not practising it & 217 & $72.53 \%$ \\
\hline 7 & Unaware of ORS & 179 & $59.66 \%$ \\
\hline 8 & Wrongly preparing ORS & 193 & $64.29 \%$ \\
\hline
\end{tabular}

193 mothers said that they one or the other time used wrong commercial preparation like Sporolac/Lactrol as ORS. Nearly $91 \%$ of the mothers did not know exactly how much ORS is to be given with each loose stool.

\section{Discussion}

Diarrhoea stays one of the main worldwide reasons for death among youngsters younger than two years. ORS is straightforward, exceedingly compelling, economical and suitable treatment for diarrheal drying out and since the presentation of ORS in 1979, there has been an unfaltering decrease in passing because of diarrheal ailments6. Diarrhoea is the frequent (typically characterized as at least three times in multi day) passage of liquid or soft stool7,8. It is the most widely recognized clinical indication of gastrointestinal infection and the second driving reason for death on the planet among kids under two years old. Unfortunately, particularly in creating nations, because of absence of legitimate information in mother, with respect to accessibility, planning and utilization of ORS, this objective is a long way from accomplished.
Although use and availability of ORS can reduce the morbidity and mortality associated with diarrhoeal diseases it is far from being highly effective especially in developing countries due to lack of awareness about availability and use of oral rehydrating solution for management of diarrhoeas. 9 Also complicating the issue is lack of understanding regarding the role of sanitation and hygiene in reducing the incidence of diarrhoea. ${ }^{[10]}$ In present study, although $75 \%$ of the mothers were educated, only 156 knew the correct method of ORS preparation and its use whereas out of the remaining mothers who knew about ORS did not know the correct method of using ORS. ${ }^{[11]}$ In fact, people adopt a wait and watch approach as it is believed the consumption of food and water increases the bulk of stools and does not provide rest to the intestine which is necessary for recovery from diarrhoea. Even some of the educated people do the same thing. ${ }^{[12]}$

\section{Conclusion}

Most of mothers do not follow use of ORS in Diarrhea practices and had lack of knowledge was found. The 


\section{Singh et al; Use of ORS in Diarrhea in Mathers with Children 02-05 Year Age Group}

knowledge regarding method of use of ORS for management of diarrhoea was found to be inadequate in this study. Though many mothers are aware that it is useful most are not aware of its method of use. More measures need to be adopted to improve this knowledge and make mothers aware about the method of use and availability of ORS.

\section{References}

1. World Health Organization. Diarrheal disease fact sheet. [Online] May 2017. [Cited 25th January 2018] Available at http://www.who.int/mediacentre/fact $\neg$ sheets/fs330/en/index.html.

2. M. Waqas Rabbani, Syed Khalid Abbas Bukhari, Sajid Mustafa et al. Awareness of Malnutrition and diarrhoeal diseases among mothers in Multan Region. Pak Paed J 2006; 30 (3).

3. Abramson JS, Abzug MJ, Adger $\mathrm{H}$ et al. Nelson Textbook of Pediatrics ELSEVIRE 2008, (18th Edition); 337: 1605.

4. Sultana A, Riaz R, Ahmed R, Khurshid R. Knowledge and Attitude of Mothers Regarding Oral Rehydration Salt. J of Rawalpindi Med Colg 2010;14(2):109-111.

5. Victora CG, Bryce J, Fontaine O, Monasch R. Reducing deaths from diarrhoea through oral rehydration therapy. Bull World Health Org 2000;78(10):1246-55.
6. Buhler HF, Ignotti E, Neves SM, HaconSde S. Spatial analysis of integrated health and environmental indicators for morbidity and mortality due to infant diarrhea in Brazil, 2010. Cad Saude Publica 2014;30(9):1921-934.

7. Mandomando IM, Macete EV, Ruiz J, Sanz S, Abacassamo F, Valles $\mathrm{X}$, et al. Etiology of diarrhoea in children younger than 5 years of age admitted in a rural hospital Southern Mozambique. Ame J Trop Med Hyg 2007;76:522-27. DOI: 10.4269/ajtmh.18-0537.

8. Diniz-Santos DR, Silva LR, Silva N. Antibiotics for the empirical treatment of acute infections diarrhea in children. Braz J Infect Dis 2006 Jun; 10 (3): 217-27.

9. Datta V, John R, Singh VP, Chaturvedi P. Maternal knowledge, attitude and practices towards diarrhea and oral rehydration therapy in rural Maharashtra. The Indian Journal of Pediatrics. 2001 Nov 1;68(11):1035-7.

10. Saurabh S, Shidam UG, Sinnakirouchenan M, Subair M, Hou LG, Roy G. Knowledge and Practice Regarding Oral Rehydration Therapy for Acute Diarrhoea among Mothers of Under-Five Children in an Urban Area of Puducherry, India. Natl J Community Med 2014;5(1):100-4.

11. Al-Trushi A.M, Saeed S, Yahya S. Knowledge, attitude and practice of mothers towards ORT; Duhok- Isra Medical Journal, 2012; 4(3):87074.

12. Jha N, Singh R, Baral D. Knowledge, attitude and practices of mothers regarding home management of acute diarrhoea in Sunsari, Nepal. Nepal Med Coll J 2006;8(1):27-30.

Copyright: () the author(s), 2019. It is an open-access article distributed under the terms of the Creative Commons Attribution License (CC BY 4.0), which permits authors to retain ownership of the copyright for their content, and allow anyone to download, reuse, reprint, modify, distribute and/or copy the content as long as the original authors and source are cited.

How to cite this article: Singh D, Lakhwani S, Gaharwar DPS. Knowledge, Attitude and Practice Study About Use of ORS in Diarrhea in Mothers with Children 02-05 Year Age Group Residing in Various Urban Slums of Bhopal City. Asian J. Clin. Pediatr. Neonatol.2019;7(3):3133.

DOI: dx.doi.org/10.21276/ajcpn.2019.7.3.9

Source of Support: Nil, Conflict of Interest: None declared. 